\title{
Warm Forming of Aluminum Alloy 2024 at Different Temperatures
}

\author{
W. J. Ali \\ O. Th. Jumah \\ Mechanical Engineering Department, Mosul University, Mosul, Iraq
}

\begin{abstract}
Forming of aluminum sheets at warm forming temperatures has been investigated as an alternative manufacturing process for improving formability compared with forming at room temperature. However, the forming technology should be developed to increase the application field, especially in the predication of formability and the failure in order to design the process and die outcomes. The results obtained during this study showed that the formability of annealed $\mathrm{Al}$-alloy (Al-2024-O) is increased by increasing temperature. Its formability is significantly improved compared with the precipitation hardened alloy (Al-2024-T3). The possibility of forming (Al-2024-T3) sheet metal at moderate temperatures, with acceptable formability and higher strength for structural parts is much better if compared to the annealed condition (Al-2024-O).
\end{abstract}

Key words : warm forming, formability, aluminum alloy (2024)

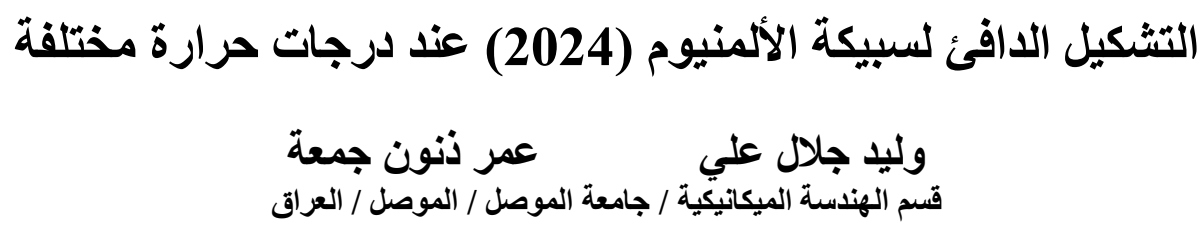

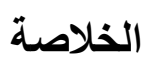

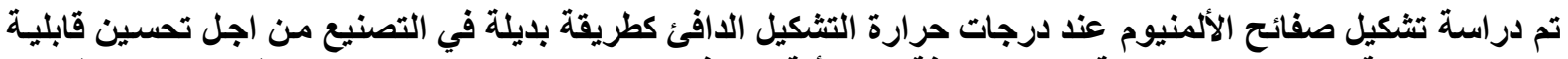

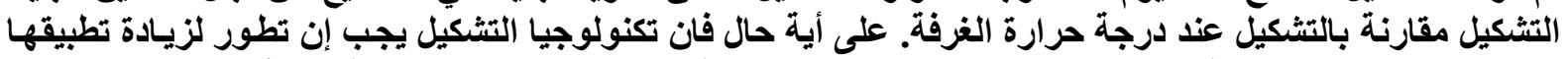

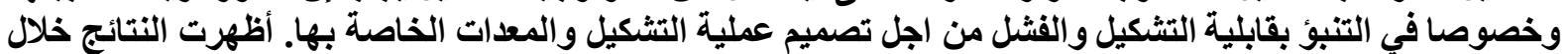

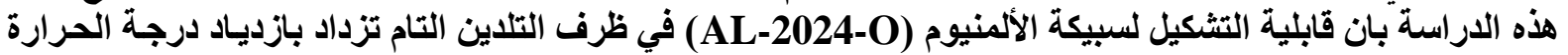

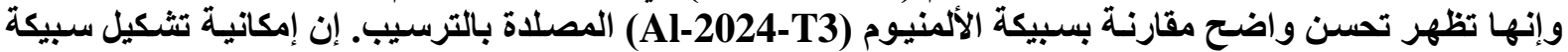

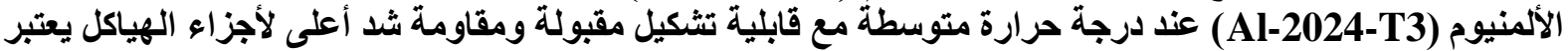
أفضل مقارنة بنفس السبيكة في ظرف التلاين التام. 


\section{Introduction:}

Sheet metal forming has a very important role in the manufacturing of complex automotive and other sheet metal components in a manner which minimizes waste material and energy utilization and permits the designers to get good results through changing intrinsic parameters as well as extrinsic factors of the forming operations for the materials [1].

However, regarding structural and body parts that highly rely on the formability of sheet metals, aluminum alloys are ranked far behind the low carbon steel in the automotive application, despite their higher strength to weight ratio and good corrosion resistance. It is clear that the limited use of aluminum alloys in the automotive industry is partly due to their poor formability at room temperature and thus, if warm forming can implement production, many of the goals related to light weighting, energy and environmental friendliness can be realized. [1,2]. Warm forming by definition is the forming of material at a temperature between cold forming and hot forming. It is the plastic deformation of a metal at temperature below the temperature range for recrystallization and above room temperature. It is an attempt to combine the advantages of both hot and cold forming into one operation [3].

In the automotive industry the demand of coupling performances with cost reduction and respect of environment is stronger and stronger. Thus, the demand for aluminum alloys as light weight metals has increased in recent years. Erdin et al. [4] investigated the warm deep drawing of AL-alloys (1050-H14, 5754-O and 6016-T4) sheets with local heating. The experimental results showed that heating process with temperatures gradient provides opportunity to draw sheets to higher deep drawing ratio levels with less press forces and to more complex geometries at the same time it renders possible to get hold of more smooth and homogenous surfaces. Naka et al. [5] investigated the effects of forming speed and temperature on the FLD experimentally for an Al-alloy (5083-O) sheet by performing stretchforming test at various forming speeds ( 0.2 to $200 \mathrm{~mm} / \mathrm{min}$ ) at several temperatures from (20 to $300{ }^{\circ} \mathrm{C}$ ). $\mathrm{Li}$ and Ghosh [2] investigated biaxial warm forming behavior in the temperature range $\left(200-350^{\circ} \mathrm{C}\right)$ of three automotive Al-alloy ( $\mathrm{Al} 5754, \mathrm{Al} 5182$ and $\mathrm{Al}$ 6111-T4) sheets.

The objectives of this work are to study the effect of forming temperatures in the range $\left(25\right.$ to $250{ }^{\circ} \mathrm{C}$ ) on formability of aluminum alloy (Al-2024) sheet metals. Forming limit diagram (FLDs) are to be constructed experimentally, following the strain paths varying from uniaxial tension to equibiaxial stretching using hemispherical punch, at room temperature and different temperatures.

\section{Experimental work and Material:}

The chemical composition of aluminum alloy (Al-2024) sheet metal used in this study, was determined by the laboratory of material testing in Aleppo University and is shown in Table (1).

Table (1) : Chemical composition of Al-2024

\begin{tabular}{|r|r|r|r|r|r|r|r|r|r|r|}
\hline Metal & $\mathrm{Al}$ & $\mathrm{Cu}$ & $\mathrm{Mg}$ & $\mathrm{Mn}$ & $\mathrm{Fe}$ & $\mathrm{Si}$ & $\mathrm{Ni}$ & $\mathrm{Ti}$ & $\mathrm{Zn}$ & $\mathrm{Cr}$ \\
\hline $\mathrm{Al} 2024$ & $\mathrm{Bal}$ & 4.805 & 1.605 & 0.566 & 0.3 & --- & 0.012 & 0.024 & 0.0205 & 0.01 \\
\hline
\end{tabular}

Forming tests were performed on a heated circular die and punch apparatus built at the Mosul technical institute workshop. The equipment involves stretching test specimen, which is clamped between circular die rings, over a hemispherical punch as shown in figure (1). 

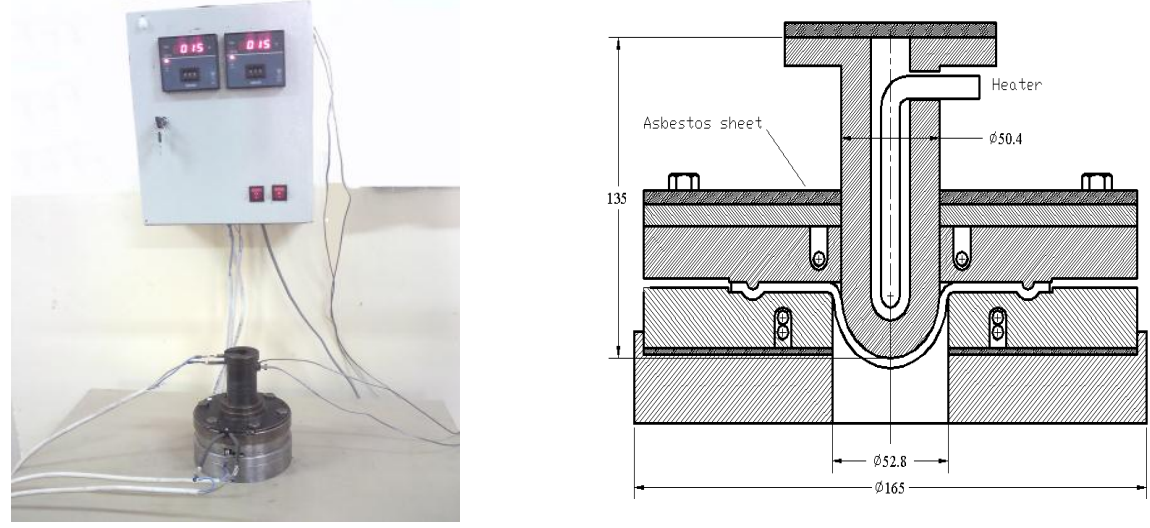

Figure (1): Photograph and schematic of hemispherical punch and die with control unit.

The die and the punch were heated by embedded heating elements. The blank holder with lock bead is used to hold the specimens in place and preventing them from sliding over the die. Thermocouples inserted into different heating areas of the die and the punch permitting temperature control using (SASSIN model XMAT) device, within a range of \pm 2 ${ }^{\circ} \mathrm{C}$. The die and punch were preheated to desired temperatures and then the sheet sample was moved into position marked on the lower die where blank holding load, using 6 bolts, was applied to tightly clamp the sheet.

\section{Deformation process:}

The procedure for performing the experiment at warm forming temperatures $(25,100$, 175 and $250{ }^{\circ} \mathrm{C}$ ) is as follows: after the preparation of the specimens each blank was clamped between the upper (blank holder) and lower die. Heat is generated with two rounded heating elements positioned around the die hole, and another heating element is located in the punch. The system was then insolated using asbestos sheets to minimize heat loss to the environment. Using the temperature control device, the desired temperature was set and maintained for a period of about (8-12) minutes until constant temperatures were achieved. After preheating to the required temperature, each specimen was deformed by the hemispherical punch until necking, with punch speed of 6 $\mathrm{mm} / \mathrm{min}$. The universal testing machine of type (AMSLER: FM2750) with a capacity $50 \mathrm{KN}$, was used as a press figure (2), in mechanical engineering department workshop.

During forming a powder graphite was used as lubricant, the punch force displacement curve was recorded

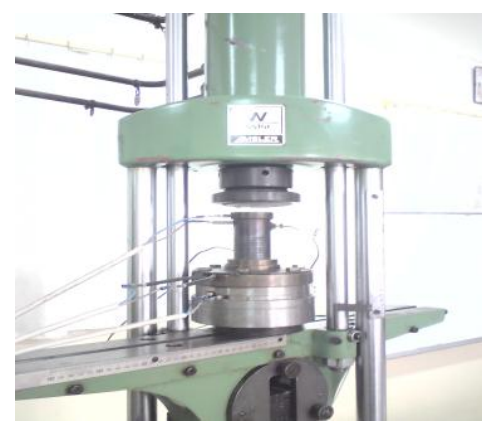

Figure (2): Photograph of heated circular die and punch apparatus. up to necking. The instant of necking of the specimen has been determined from the drop in the force. This process was repeated several times for each test temperature.

\section{Forming limit diagrams:}


FLDs have been constructed to describe the strain states. According to modified Hecker method [6] used by many researchers among them $[7,8]$, the shapes of the specimens have been chosen in such a way to cover the whole range of the forming limit, varying from uniaxial tension to equibiaxial stretching. The major $\left(\mathrm{d}_{1}\right)$ and minor $\left(\mathrm{d}_{2}\right)$ diameters of printed circles, on the specimens surface, are determined by measurement carried on real deformed sheets using optical strain measurement as shown in figure (3), in civil engineering department- Mosul University. This technique based on curve fitting equation, the major $\left(\epsilon_{1}\right)$ and minor $\left(\epsilon_{2}\right)$ principal engineering strains of the resulting shapes can be determined and employed to plot FLDs.

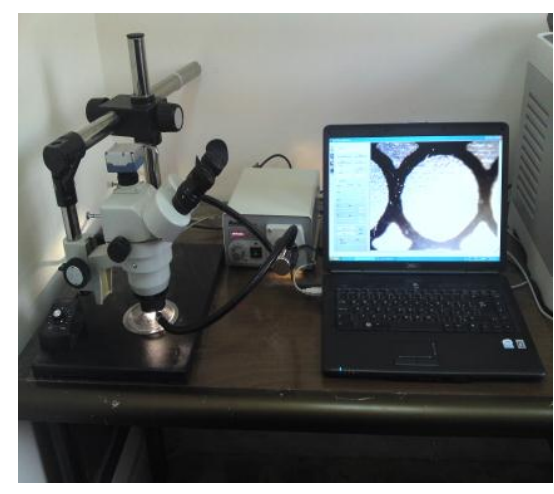

Figure (3): The equipment of the optical strain measurement system.

$\epsilon_{2}=\ln \left(\mathrm{d}_{1} / \mathrm{d}_{0}\right)$

$\epsilon_{2}=\ln \left(\mathrm{d}_{2} / \mathrm{d}_{0}\right)$

\section{Results and discussion:}

Tests were performed, at different temperatures between 25 and $250{ }^{\circ} \mathrm{C}$, The results are presented for as received (Al-2024-T3), full annealed (Al-2024-O) conditions. When (Al2024-T3) sheet is deformed the punch displacement was low at room temperature and slightly increases with increasing of forming temperature until $175^{\circ} \mathrm{C}$ as shown in figures (4a,5-a).

This effect revealed that dynamic precipitation during the tests greatly enhanced the strength of (Al-2024-T3) alloy and the dislocations not being able to move easily through the coherence phase or second phase particles and it can be shown that high impedance to the dislocation motion, i.e. high hardening is to be expected when the spacing between the particles is equal to the limiting radius of curvature of moving dislocation line. It means that the high strength developed when the number of particles and their size distribution combine to promote the smallest average inter particles separation [9]. At $250{ }^{\circ} \mathrm{C}$ further aging occurs and reduce the ductility of the metal. The reduction of the ductility and punch displacement is linked to the decrease in the strain rate hardening capacity with aging, same results obtained by Gargali, M. et al [10] they found that hot workability of (Al-2014) alloy increases with increasing temperature to $200{ }^{\circ} \mathrm{C}$, and the ductility tends to decrease with increasing temperature due to the hot brittleness caused by second phase conversely, Novotny, S. and Geiger, M. [11] recommended that the heat treatable materials, like Al-alloy (Al-6016) must not be exposed to more than $200{ }^{\circ} \mathrm{C}$ as more aging take place at elevated temperature and that's agree with results obtained.

The decreasing of punch displacement at $250{ }^{\circ} \mathrm{C}$, may have several explanations. First, the high density of precipitates and higher stress level in the aged alloy will probably reduce the elongation. Second, the reduced strain hardening exponent and hardening capability of the metal is expected to increase the voids growth, and localization of strain to the precipitates zones may also contribute to lower ductility. This is based on the assumption that the voids may nucleate at grain boundary precipitates and that the criterion for nucleation is a critical normal stress at the particles matrix interface [12,13].

By using TEM with backscattered electrons technique precipitations have been observed on grain boundaries as shown in figure (6), the nucleation at these precipitations 
sites is instantaneous even at $250{ }^{\circ} \mathrm{C}$ in spite of the low solute diffusion. [14]. Plastic instability or localization in aluminum alloy in softening, occurs due to the interaction between different factors such as material hardening and coalescence of micro-cracks or voids. Voids nucleation usually occurs at inclusions and second phase particles in a metallic matrix, it commence when the softer regions in a material deformation deform more rapidly than other regions and represents a drastic change in material deformation from relatively uniform to a non-uniform deformation then the punch displacement at $250{ }^{\circ} \mathrm{C}$ is reduced $[15,16]$. On other hand, The annealing decreases the strength of metal and increases the ductility. The (Al-2024-O) alloy is initially in the fully annealed condition, this reflects that no precipitation happened therefore the punch displacement of (Al-2024-O) sheet metals increases with raising temperature until $250{ }^{\circ} \mathrm{C}$ as shown in figures (4-b,5-b).

\section{The forming limit diagram (FLD):}

The aluminum sheet metals (Al-2024-T3, Al-2024-O) are experimentally deformed following the procedure explained earlier. FLDs were determined at different forming temperatures $\left(25-250{ }^{\circ} \mathrm{C}\right)$ by measuring the principal strains of printed circles on sheets surfaces using optical strain measurement which is shown in figure (3). The FLDs are plotted as shown in figures (7-a, and b). The FLCs were raised with the temperature for the two sheet metals in the whole strain paths from uniaxial tension to equbiaxial stretching. The FLDs of (Al-2024-T3) in the temperatures range $\left(175-250^{\circ} \mathrm{C}\right)$ are very close to each other as shown in figure (7-a), this probably means that the forming limit strain level, for the Al-alloy under these conditions (treatment T3), is increased with increasing temperature up to $175{ }^{\circ} \mathrm{C}$, but it exhibits no improvement at higher temperature, this agrees with the results obtained by $\mathrm{Li}$, D. and Ghosh, A. [2].

When FLDs of (Al-2024-T3) sheet metal are compared with FLDs of (Al-2024-O) sheet metal in full annealing condition, the formability of (Al-2024-O) sheet metal is higher than that for (Al-2024-T3) sheet metal as shown in figure (8-a,b,c and d) for all testing temperatures as was explained earlier.

Generally, formability of (Al-2024-O) sheet metals at the studied forming temperatures is better than that for (Al-2024-T3) sheet metal. It is found that the FLDs of (Al2024-O) sheet metals raise with increasing temperatures as metals soften with more ductility and no precipitation hardening takes place, which is not the case that occurs with (Al-2024T3) sheets metal.

\section{Conclusions:}

The effect of temperatures in the range $\left(25-250{ }^{\circ} \mathrm{C}\right)$ on the formability of Al-alloy (Al2024-T3 , O) sheets have been investigated. The following conclusions can be drawn :

1. The formability is increased for the tested sheet metals with the temperatures, and a more formability improvement is found in the (Al-2024-O) sheet metal compared with (Al-2024-T3).

2. The formability and flow stress of (Al-2024-T3) sheet metal is good at moderate temperature until $175{ }^{\circ} \mathrm{C}$. The possibility to form it at moderate elevated temperature with acceptable formability and higher strength for structural parts is better if compared to the annealed state (Al-2024-O). 


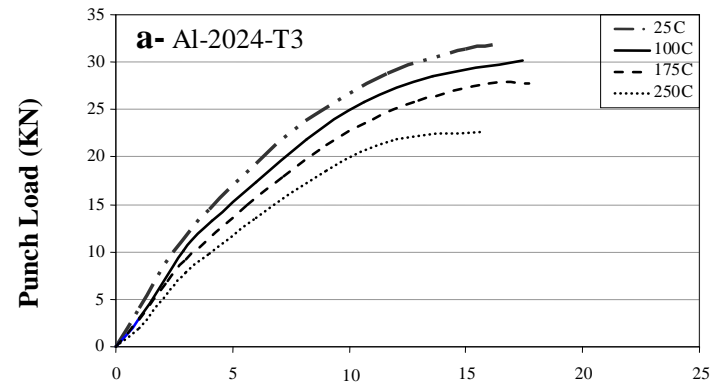

a

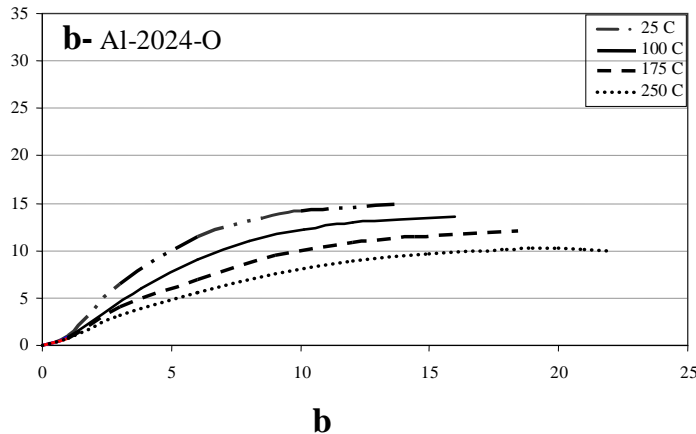

b

Punch displacement (mm)

Figure (4): Punch load vs. punch displacement at several temperatures

a- $\mathrm{Al}-2024-\mathrm{T} 3$

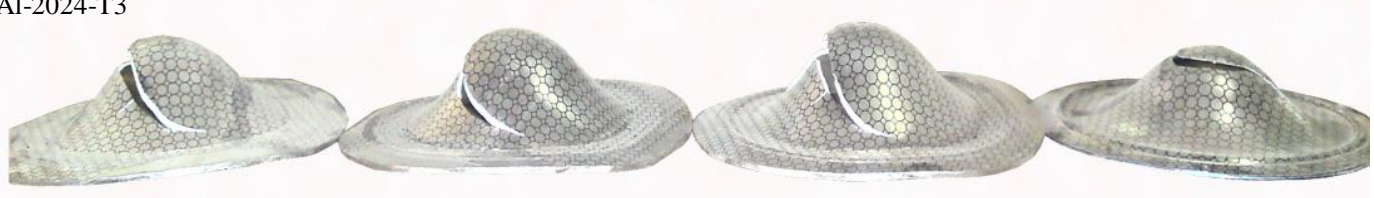

b- $\mathrm{Al}-2024-\mathrm{O}$

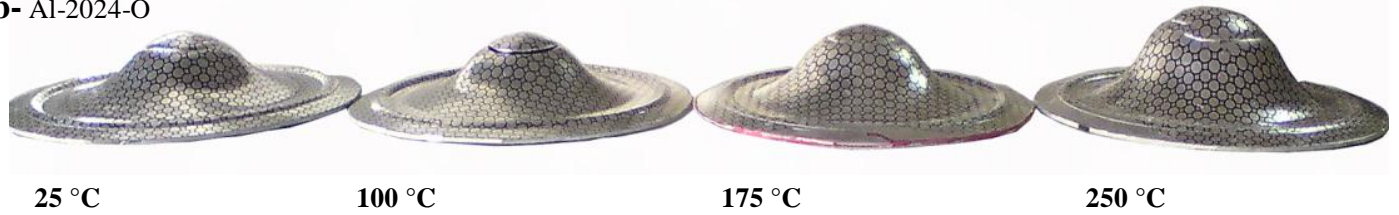

Figure (5): Punch stretch experimental results at several temperatures for Al2024-T3 and Al-2024-O
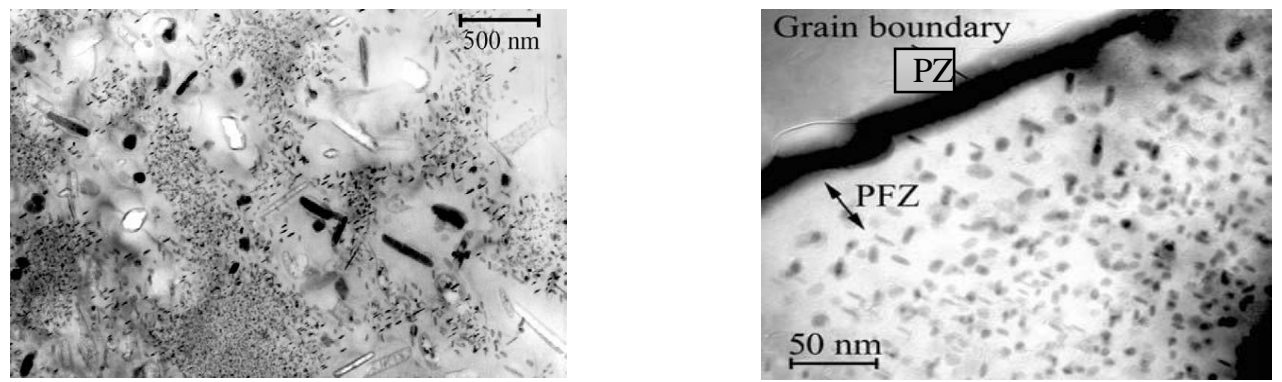

Figure (6) : TEM micrograph showing a Precipitate Zone around a grain boundary in an Al$\mathrm{Zn}-\mathrm{Mg}-\mathrm{Cu}$ alloy. Precipitate Zone around a grain boundary [14]
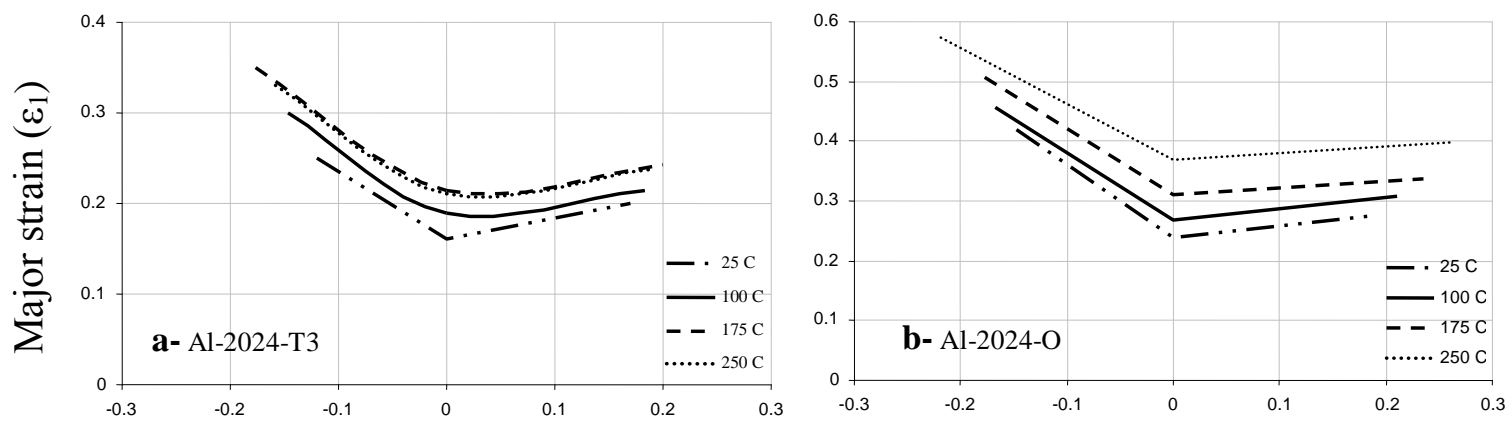

Figure (7): Experimental FLDs of Al-2024-T3 and Al-2024-O at different 

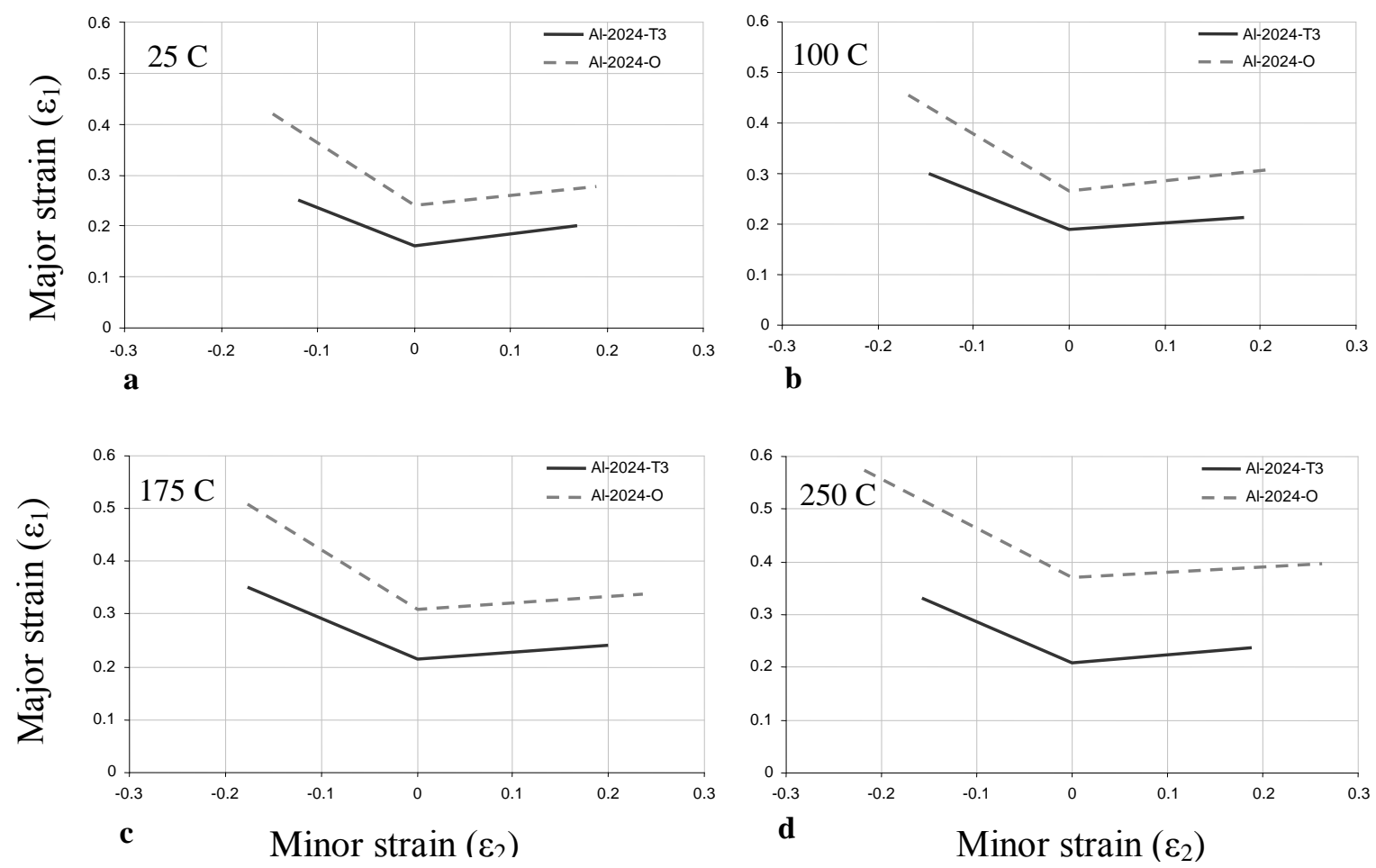

Figure (8): Comparison of FLDs of Al-2024-T3 and Al-2024-O at different temperatures

\section{References:}

1. Panda, S., Kumar, D., Kumar, H. and Nath, A.," Characterization of tensile properties of tailor welded IF steel sheets and their formability in stretch forming ", J. Mater. Process. Technol., 183, 321-332 (2007)

2. Li, D. and Ghosh, A., "Biaxial warm forming behavior of aluminum sheet alloys", J. Mater. Process. Technol., 145, 281-293 (2004)

3. Turetta, A., Bruschi, S. and Ghiotti, A.," Investigation of $22 \mathrm{MnB5}$ formability in hot stamping operations”, J. Mater. Process. Technol, 177, 396-400 (2006)

4. Erdin, M., Aykul, H. and Tunalioglu, M.," Forming of high strength low formability metal sheets at elevated temperatures", Math. Comp. Application, 10, 331-340 (2005)

5. Naka, T., Torikai, G., Hino, R. and Yoshida, F., "The effects of temperatures and forming speed on the forming limit diagram for type 5083 alumnuim magnesium alloy sheet”, J. Mater. Process. Technol., 113, 648-653 (2001)

6. Al kaissy, F.,A., "Formability in sheet metals by finite element method",Ph.D thesis, Production and metallurgical Engineering, University of Mosul (2006).

7. Alsultan, Th.,F., "The effects of prestrain and some heat treatments on the forming limit diagram of aluminum alloy sheets (2024-T3) ", M.Sc. thesis, Production and Metallurgy, Uneversity of Mosul. (2007)

8. Adries, A.,O.,"Study of factors affecting the deformation of forming limit diagram for sheet metals", M.Sc. thesis, Applied mechanics and Production, Uneversity of Mosul, (2005)

9. Jalal, Sh., R., "Thermomechanical treatments on the mechanical properties and stress corrosion cracking of certain aluminum alloys", Ph.D thesis, Engineering Metallurgy, University of Salahaddin- Erbil (2004)

10. Gargali, M. and Aksakal, B.," Effect of various station treatment on the hot workability of ingot aluminum alloy Al-2014 ”, Matr. Sci. Eng., 254, 189-199 (1998) 
11. Novotny, S. and Geiger, M.," Process design for hydro-forming of lightweight metal sheets at elevated temperatures", Mater. Process. Technol., 138, 594-599 (2003)

12. Pedersen, K., Roven, H., Lademo, O. and Hopperstad, O.," Strength and ductility of aluminum alloy AA7030", Mater. Sci. Eng., 473, 81-89 (2008)

13. Chepko, C., "An Experimental and Analytical Study of the Properties of Precipitation Hardening Aluminum Alloys", Ph.D., Materials Research, University of the Pacific. (2000)

14. Godard, D., Archambault, P., Aeby-Gautier, E. and Lapasset, G.," Precipitation sequences during quenching of the AA7010 alloy”, Acta Materials, 50, $2319-2329$ (2002)

15. Hadianfard, M., Smerd, R., Winkler, S. and Worswick, M. "Effects of strain rate on mechanical properties and failure mechanism of structural Al-Mg alloys", Mater. Sci. and Eng. , 492, 283-292 (2008)

16. Finch, D., Wilson, S. and Dorn, J., "Deep drawing aluminum alloys at elevated temperatures", Trans. ASM, 36, 254-289 (2003) 